\title{
ORFEU E A IMAGEM MITOLÓGICA DO POETA ENTRE VIRGÍLIO E HORÁCIO
}

\author{
Alexandre Prudente Piccolo ${ }^{1}$
}

\section{Resumo}

Personagem caro a poetas de diversas gerações, Orfeu representa diferentes facetas associadas aos poderes da poesia. Desde um civilizador mitológico até o emblema máximo de poeta mítico, o arquétipo de Orfeu incorpora a força primeva da poesia, capaz tanto de domar animais selvagens e de encantar pedras e árvores, quanto de descer ao mundo dos mortos e de sair ilesa de lá. A imagem de Orfeu nos textos de Virgílio e Horácio pode revelar curiosas e instigantes relações, que permitem enriquecer a leitura de seus respectivos poemas, como sugere o presente artigo.

Palavras-chave: Orfeu; Horácio; Virgílio; Poesia Latina.

\begin{abstract}
This article investigates how Orpheus, such an important character to many poets from different generations, represents distinct aspects associated with the power of poetry. From the image of a mythological civilizer to the highest symbol of a mythic poet, Orpheus' archetype incorporates the primeval power of poetry, capable of both taming savage animals, and enchanting rocks and trees, as descending into the underworld, and escaping from there untouched. The image of Orpheus in the texts of Vergil and Horace reveals curious and stimulating relations, which might enrich their own readership.
\end{abstract}

Keywords: Orpheus; Horace; Virgil; Latin Poetry.

\footnotetext{
1 Doutor em Linguística na área de Estudos Clássicos pelo Instituto de Estudos da Linguagem (IEL) da Unicamp. Além de período sanduíche (2012-2013) no Corpus Christi College (Oxford, UK), conquistou bolsaprêmio (2011) para jovens pesquisadores da Fundação Hardt (Genebra, Suíça) para estudo da Antiguidade Clássica. Foi professor temporário (2014) de língua e literatura latina na Universidade de São Paulo (USP). Sem abandonar o gosto e o interesse pela literatura brasileira, dedica-se ao estudo e à tradução da poesia greco-latina do período augustano.
} 


\title{
INTRODUÇÃO
}

Muito antiga é a origem de Orfeu. ${ }^{2}$ Figura mitológica da Trácia associada a antigas culturas xamânicas na Ásia Menor, a personagem órfica reunia atributos de poeta e adivinho (mántis, "vidente, profeta") e se dispersava por uma Grécia plural e multifacetada, que evitou separá-los. ${ }^{3}$ Em Roma, a lenda de Orfeu tornou-se não só importante como profícua à poesia de escritores vindouros, como os poetas do período augustano, fiéis tributários da herança grega nos primórdios do Império. Por exemplo, Propércio ecoa, à moda alexandrina, a voz da tradição acerca de Orfeu no terceiro volume de suas Elegias:

\author{
Orphea detinuisse feras et concita dicunt \\ flumina Threicia sustinuisse lyra; \\ saxa Cithaeronis Thebanam agitata per artem
}

sponte sua in muri membra coisse ferunt;

(Elegia 3.2.3-6)

Orfeu deteve as feras - dizem - e os caudalosos rios reteve com sua lira trácia; as pedras do monte Citéron, conduzidas por sua arte, voluntariamente juntaram-se como partes da muralha - contam.

Essa refinada técnica musical, capaz de comover os mais duros elementos da natureza, as pedras, ${ }^{4}$ vem se transformar, por isso mesmo, em símbolo da força persuasiva e envolvente do canto poético - traço central e comum em relatos de diferentes povos, textos e representações da Antiguidade. O amansador de animais ferozes dá mais um exemplo à

\footnotetext{
${ }^{2}$ Vejam-se Grimal (1993: 340-342) para apontamento de fontes antigas, Burgess (2005: 344) para a menção de um épico órfico, e os artigos do volume editado por Ogden (2007: 94-9; 148; 340) para várias considerações religiosas.

${ }^{3}$ Um instigante panorama dessa origem e transformação pode ser lido em Eudoro de Souza (2013), em especial no capítulo 6, "A mensagem de Orfeu."

${ }^{4}$ Ainda que Orfeu como "construtor" das muralhas de Tebas destoe do relato épico homérico: nem Homero nem Hesíodo mencionam Orfeu. Contudo, vale a pena conferir Odisseia 11.263s., além de Horácio Ode 3.11.1-2 e Ars Poetica 394-5, tratadas a seguir.
} 
proeza, cuja descrição parece corriqueira na poesia latina, tal como um dos retratos de Orfeu em Virgílio. ${ }^{5}$

Várias vezes mencionado nas Éclogas, ${ }^{6}$ Orfeu recebe, de fato, tratamento minucioso ao fim do livro IV das Geórgicas, em que sua história se insere na história de Proteu a Aristeu. Parte mais alexandrina de toda obra, repleta de digressões e relatos épicos, o quarto canto traz um episódio introduzido no interior de outra narração, como uma espécie de "moldura". Ao buscar motivos para a morte de suas abelhas, o pastor Aristeu vem interrogar o deus marinho Proteu. Descobre, então, Aristeu ser ele próprio a causa da destruição de suas abelhas, depois de ter provocado, involuntariamente, a morte de Eurídice, amada de Orfeu. ${ }^{7} \mathrm{~A}$ fábula de Orfeu e Eurídice, incrustada na resposta de Proteu ao pastor, faz lembrar outra narrativa dentro da narrativa: a história de Teseu e Ariadne, abandonada na ilha de Naxos e raptada, então, por Dioniso, episódio brilhantemente narrado, sob o pretexto de descrever uma cena bordada num véu matrimonial, no epitalâmio de Tétis e Peleu no poema 64 de Catulo.

Procedimento típico de narrativas populares (lembrem-se as Mil e Uma Noites), a série de episódios incrustados permite que narradores e poetas criem atavios infinitos no tecido de seus textos. Dentre tantos efeitos possíveis, ressalta-se a mestria nas artes de composição e orquestração do conjunto da narrativa. No exemplo virgiliano, desde as relações entre os emblemas de Orfeu e Aristeu, colocando em tensão a narrativa "moldura" e sua fábula, ${ }^{8}$ até a súbita morte de Eurídice, a descida (catábase) pela morada infernal e todo o ciclo poético de vida, morte, superação e afã momentâneos, frustração duradoura e "nova" morte, todas as partes e detalhes do texto virgiliano propiciam um olhar provocador da imagem mitológica do poeta, traçada (sem que se esqueça) por outro poeta.

\footnotetext{
${ }^{5}$ Cf. mulcentem tigris, "amansando os tigres" - Geórgicas 4.510. Célebre é o mosaico Romano, datado do século III d.C., que retrata Orfeu com uma lira às mãos circundado por diversos animais selvagens, obra exposta no Museu Arqueológico "Antonio Salinas" de Palermo.

${ }^{6}$ Vejam-se Ec. 3.46 (delicada écfrase numa taça, prêmio da disputa entre pastores-poetas): Orpheaque in medio posuit, siluasque sequentis "e, no meio, ele cinzelou Orfeu e as selvas seguindo-o"; Ec. 4.55 (excelso exemplar de poetas notáveis, dentre outros): non me carminibus uincat nec Thracius Orpheus "não me vencerá nos versos o trácio Orfeu", além da mãe Calíope mencionada no v. 57; Ec. 6.30 (novamente, exemplo elevado entre míticas divindades poéticas): nec tantum Rhodope miratur et Ismarus Orphea "nem tanto os montes Ródope e Ísmaro admiram Orfeu"; Ec. 8.55-6 (padrão de excelência poética): sit Tityrus Orpheus, / Orpheus in siluis "seja Títiro um Orfeu, um Orfeu nas selvas." Neste texto, todas as traduções são minhas, salvo quando explicitado o tradutor.

${ }^{7}$ Traz valiosas reinterpretações o estudo de Conte (1986), ampliado mais tarde (cf. Conte 2007).

${ }^{8}$ Cf. Segal (1989: 20-24), que explora oposições variadas entre forças simbolizadas pelos personagens: vítima vs. algoz; amor consolador vs. paixão desenfreada; emoção individual vs. ação externa coletiva etc.
} 
Por exemplo, chama atenção o estupor (cf. stupuere) que a poesia encantadora de Orfeu é capaz de provocar em sua peculiar audiência, os seres mitológicos do submundo:

\author{
quin ipsae stupere domus atque intima Leti \\ Tartara caeruleosque implexae crinibus anguis \\ Eumenides, tenuitque inhians tria Cerberus ora, \\ atque Ixionii uento rota constitit orbis.
}

(Geórgicas 4.481-4) ${ }^{9}$

A dicção ao mesmo templo exuberante e simples, o colorido viçoso na sintaxe entrelaçada das cobras e o movimento de estupor (não sem antecipações verbais) rumo à completa paralisia criam, aqui, um equivalente vívido da magia enérgica da própria canção órfica: é a voz de Proteu (narrador das proezas de Orfeu, no trecho, para o pastor Aristeu) que mascara e revela momentaneamente os dotes poéticos de Virgílio, cujos torneios enfeitiçam olhos e ouvidos do leitor romano e moderno. Se tais seres infernais param diante do encanto da poesia de Orfeu, nós ficamos estupefatos frente ao texto poético de Virgílio.

Em ampla medida, o poeta autor vem concretizar a voz do poeta sofredor, cuja música é ao mesmo tempo ação literal e simbólica no processo de perda, morte e renovação da vida. Orfeu não é capaz de resgatar sua amada do mundo dos mortos, porém não deixa de levar seu empenho poético às últimas consequências. Por outro lado, “o poeta identifica-se com as leis impessoais da natureza”, como nota Segal (1989: 7): "sua música é eterna, reflete os padrões atemporais do mundo ao invés de sua própria vida emocional.” A reverberação da voz do poeta, sob uma cadeia de vozes poéticas, presas ou não ao mesmo texto, ultrapassa fronteiras tanto entre os mundos de vivos e mortos, quanto do tempo cronológico, tornando o mito de Orfeu e o texto de Virgílio ainda mais elaborado e, por isso mesmo, múltiplo e vigoroso.

\footnotetext{
${ }^{9}$ Até mesmo as próprias moradas ficaram estupefatas, e os íntimos tártaros / de Lete, e as Eumênides envoltas nos cabelos com cerúleas / cobras; e deteve-se boquiaberto Cérbero de três cabeças, / e cessou com o vento a roda de Ixião.
} 


\title{
UM ESPELHO ENTRE PÍNDARO E ORFEU: ODE 1.12
}

Em um poema cujo início emula a abertura da segunda Olímpica de Píndaro, ${ }^{10}$ Horácio passa do poderoso introito acerca da força mitológica da poesia, materializada na musa Clio (destinatária do "proêmio" da ode), para uma mítica e convencional descrição do poeta Orfeu entre os bosques, parando o curso dos rios (como em Propércio, acima) e encantando árvores:

\author{
Quem virum aut heroa lyra vel acri \\ tibia sumis celebrare, Clio? \\ quem deum? cuius recinet iocosa \\ nomen imago \\ aut in umbrosis Heliconis oris \\ aut super Pindo gelidove in Haemo, \\ unde vocalem temere insecutae \\ Orphea silvae \\ arte materna rapidos morantem \\ fluminum lapsus celerisque ventos, \\ blandum et auritas fidibus canoris \\ ducere quercus? \\ (Ode 1.12.1-12) ${ }^{11}$
}

Alusiva ao hino grego, a indagação inicial desloca-se sutilmente para a lírica descrição do encanto exercido pela poesia órfica. A "sutileza" surge em meio a uma peculiar geografia: após mencionar montes caros à tradição, ${ }^{12}$ o poeta passa, natural e fisicamente (cf. unde, v. 7), para a imagem de Orfeu encantando com sua música as próprias árvores. De modo quase imperceptível, a ode interliga a força mítica dessa arte primeva com a lírica de

\footnotetext{
${ }^{10} \mathrm{Na}$ tradução de Frederico Lourenço (vv. 1-2): "Hinos soberanos da lira! / Que deus, que herói, que homem celebraremos?" O eco intertextual é notado desde o século III d.C. por Porfirião (apud Meyer 1874, ad loc.). Comentários e vasta indicação bibliográfica encontram-se, por exemplo, em Nisbet e Hubbard (1970: 142ss.), Cavarzere (1996: 147ss.) e Holzberg (2007: 133).

${ }^{11}$ Que homem ou herói, com a lira ou a aguda / tíbia, escolhes celebrar, Clio? / Que deus? A jocosa "imagem" (i.e., Eco) recantará / o nome de quem, / seja nas margens umbrosas do Hélicon, / seja sobre o Pindo ou no gélido Hemo, / onde os bosques seguiram cegamente / Orfeu, canoro, / que com arte materna retardava os rápidos / cursos dos rios e os céleres ventos, / a conduzir, brando, atentos carvalhos / com seus sonoros acordes?

${ }^{12}$ Embora distantes, os três montes da ode são notadamente poéticos: o Pindo, na fronteira entre a Tessália e o Epiro, é uma tradicional morada das musas (citações diversas em Nisbet e Hubbard 1970: 147), ao passo que, no Hélicon, Hesíodo diz ter recebido inspiração das musas enquanto pastoreava (cf. Teog. 22s.). Berço do poeta Orfeu é o monte Hemo, na Trácia, cujas inscrições locais também celebram-lhe o poder sobre a natureza.
} 
Píndaro, sob a máscara duma relação intertextual. O motto inicial em forma de pergunta transforma-se em matéria poética concreta, sem que tal descrição soe como uma resposta definitiva: é apenas a primeira. As perguntas pindáricas transmutam-se na reformulação horaciana e corporificam um robusto emblema poético-mitológico. O primeiro nome a ser lembrado é o de Orfeu. Aos olhos do leitor ciente da alusão refinada, Píndaro e Orfeu passam a se encontrar entre a abertura e a matéria (a res, na terminologia antiga) primeira da mesma ode. $^{13}$

Além da sugestão preciosa da técnica poética ancestral (cf. arte materna, v. 9), ${ }^{14}$ é a ambientação natural nessa sugestiva geografia que se destaca: os rios são rápidos (v. 9), assim como os ventos (v. 10), ao passo que Orfeu é suave, agradável, brando (blandum, v. 11). O poeta anda num ritmo diferente do ritmo do mundo. Vale notar que os carvalhos se personificam por meio do adjetivo auritas (v. 11), atavio que contrabalanceia o signo da voz (cf. vocalem, v. 7) atribuído ao mitológico poeta, capaz de fazer que o sigam os bosques selvagens. Eis que a natureza torna-se mais que mera natureza: é um público atento, que se deixa levar (insecutae, v. 7; ducere, v. 12) por uma força maior.

A confiança de Orfeu em suas persuasivas cordas musicais (cf. fidibus canoris, v. 11, em fim de verso) está presente também em Virgílio, quando Eneias, receoso de adentrar nos domínios do Hades, invoca-o dentre os heróis que conseguiram ali entrar e retornar dali:

si potuit manis arcessere coniugis Orpheus

Threicia fretus cithara fidibusque canoris

(Eneida 6.119-20, ênfase acrescida)

se Orfeu pôde evocar a alma da esposa

\footnotetext{
${ }^{13}$ Segundo Segal (1989: 202), há uma única referência a Orfeu em Píndaro (Treno 3.11-2), em que o poeta mítico é dito "aquele da espada dourada, filho de Eagro."

${ }^{14}$ Parte da tradição diz que Orfeu era filho de Calíope com o rei Eagro (com Apolo, diz outra parte), mas a menção a Clio ("musa da fama, da glória, da celebração" - em algumas representações, com uma lira nas mãos), no início da ode, pode não ser gratuita. Cf. Grimal (1993: 340-342) e Nisbet e Hubbard (1970: 146).
} 
confiado na cítara trácia e suas cordas canoras

Nos versos horacianos, contudo, não se adentra o mundo dos mortos - tal qual se fará em odes tratadas a seguir. $\mathrm{O}$ encanto poético também é um puro elemento de feitiço ou magia natural, espécie de pretexto que une, alusiva e narrativamente, dois poetas distintos. A força da arte poética sobre a natureza corresponde a um poder de fascínio e encantamento que se mistura ao poder celebrador da poesia de Píndaro, que eterniza as personagens imortalizadas por seus versos. Se, por um lado, as "cordas canoras" da lira soam como instrumentação quase formular, comum a gêneros distintos (também aos líricos), por outro, a sedução exercida por Orfeu transmigra-se, de modo furtivo e delicado, para a celebração enérgica da poesia pindárica, aludida na abertura da ode. Trocando em miúdos, a ode alude a Píndaro e logo passa à imagem de Orfeu e sua poesia inigualável. Os dois poetas, o histórico e o mitológico, revelam-se cúmplices e artífices de um mesmo poder poético, que fascina e celebra a um só tempo.

Se Horácio soube reunir num único poema antigas forças poéticas e equipará-las, sua mestria é capaz de aproximar também amigos e poetas, vivos e mortos.

\title{
VIRGÍLIO CHOROSO, MAIS DOCE QUE ORFEU: ODE 1.24
}

No belo lamento que compõe em homenagem ao falecido amigo Quintílio, Horácio recorda como essa morte veio trazer tantas lágrimas ao poeta Virgílio, seu amigo próximo. ${ }^{15}$ Eis que o poeta lírico cogita uma hipotética "proeza mitológica" em seus versos:

\author{
quid si Threicio blandius Orpheo \\ auditam moderere arboribus fidem, \\ num vanae redeat sanguis imagini, \\ quam virga semel horrida, \\ non lenis precibus fata recludere,
}

\footnotetext{
${ }^{15}$ Lembre-se do afetuoso epíteto ao celebrar Virgílio: animae dimidium meae ("metade da minha alma"), Ode 1.3.8.
} 
nigro compulerit Mercurius gregi?

(Ode $1.24 .13-8)^{16}$

A ressonância dos versos acima coloca em harmonia Virgílio, Quintílio e Orfeu. Em outras palavras, mesmo que o poeta das Geórgicas descesse aos infernos e tentasse resgatar o falecido amigo usando o poder encantatório da lira órfica, não seria possível libertá-lo da mansão dos mortos. Se Orfeu foi descrito, no poema anterior, como brando (cf. blandum, ode 1.12.11), Virgílio e sua proeza poética tornam-se, aqui, ainda mais doces e suaves no advérbio blandius (v. 13). Ainda assim, não haveria sucesso ao se tentar reviver os mortos como acontece com o Orfeu virgiliano. Eis que a ode conclui, em tom mais realista e sentencioso, por uma nota sapiencial aos que devem continuar a viver: levius fit patientia / quidquid corrigere est nefas. ${ }^{17}$

Lembre-se, contudo, de que Virgílio canta na Eneida a passagem de seu herói romano pelo mundo infernal, donde ele sai vivo. Na catábase do canto VI, após deixar as profundezas tenebrosas e adentrar os campos elísios, Eneias passa a ver em seu percurso ditosas figuras lendárias, dentre as quais o próprio Orfeu entoando seu instrumento:

nec non Threicius longa cum veste sacerdos
obloquitur numeris septem discrimina uocum, ${ }^{18}$
iamque eadem digitis, iam pectine pulsat eburno.

(Eneida 6.645-7)

E o trácio sacerdote (i.e., Orfeu), com sua longa veste, acompanha seu próprio canto com a lira de sete cordas e, ora com os dedos, ora com o plectro ebúrneo, pulsa-a.

O título de sacerdote dignifica o vate mitológico: imortal dentre os bem-aventurados, suas qualidades poéticas continuam a ressoar no mundo dos mortos. Esse traço sagrado (note-

\footnotetext{
${ }^{16}$ E se mais brando que o trácio Orfeu / tocasses a lira, ouvida até pelas árvores: / acaso voltaria o sangue ao espectro vazio, / que, de uma vez, com o horrendo caduceu / Mercúrio juntou ao negro rebanho, / inflexível aos rogos para reabrir os fados?

${ }^{17}$ Ode 1.24.19-20: "a paciência torna mais leve o que quer que não se pode emendar."

${ }^{18} \mathrm{Cf}$. nota 31 , adiante, sobre o número (sete) das cordas.
} 
se a raiz sacer, v. 645) ${ }^{19}$ de Orfeu traz algo de análogo com sua descrição noutra obra de Horácio:

\author{
silvestris homines sacer interpresque deorum \\ caedibus et victu foedo deterrruit Orpheus, \\ dictus ob hoc lenire tigris rabidosque leones;
}

(Arte Poética 391-3) 20

Poeta civilizador, que tirou os homens da barbárie (identificados com as feras por meio do adjetivo silvestris, v. 391) e os afastou da selvageria da alimentação antropofágica, ${ }^{21}$ Orfeu é o primeiro da lista horaciana em que se exemplificam avanços e benefícios conferidos pela poesia à humanidade. ${ }^{22}$ Embora não tenham sido capazes de, propriamente, ressuscitar os mortos, os poetas valeram-se de seus traços divinos não só para aprimorar o engenho da natureza humana, mas também para conferir imortalidade a personagens, episódios e objetos por meio do poder mitológico de seus cantos.

Por exemplo, nos versos da ode 1.24 citados acima, o feito grandioso do poeta lírico equipara-se a uma proeza divina, de feições épicas: Horácio imortaliza tanto o amigo vivo em seu momento de dor profunda, quanto a memória do amigo morto, além de conferir alento aos que sofrem pelos pesares da morte. É o poeta lírico que, silenciosamente, iguala-se a um vate épico, fazendo de seus amigos personagens de um triste "poema didático", em que está vedado o sucesso e a própria hipótese de "descida ao Hades.” Mais uma vez, é Horácio que equipara um poeta real (ou histórico, se preferir), seu contemporâneo, a um poeta mitológico, como se dissesse: "meu caro Virgílio, tu cantas mais docemente que o próprio Orfeu; e, como ele, não serás capaz de trazer de volta nosso amigo querido."

\footnotetext{
${ }^{19}$ Veja-se sobretudo Benveniste (1969: 187-92) para uma distinção seminal entre sacer e sanctus.

${ }^{20}$ Intérprete sagrado dos deuses, Orfeu afastou os homens selvagens das matanças e do alimento horrendo; diziase, por isso, que ele abrandava os tigres e os raivosos leões.

${ }^{21}$ Cf. Brink (1971: 384ss.).

${ }^{22}$ A lista passa por Anfião (Thebanae conditor urbis, "fundador da cidade de Tebas", v. 394), Homero e Tirteu.
} 
Esse mundo dos mortos, contudo, é palco de outros momentos líricos, em que Orfeu não mais é evocado (nominalmente), mas em que pairam os ares de sua presença mitológica sob diferentes disfarces poéticos.

\section{ALCEU E SAFO SOB O DISFARCE DE ORFEU: ODE 2.13}

Depois de recordar a quase-morte quando uma árvore por pouco não caíra sobre sua cabeça, Horácio supõe fantasticamente sua entrada no reino de Prosérpina, onde encontra, em meio às almas doutros mortos, os fantasmas de Alceu e Safo, ilustres líricos do passado:

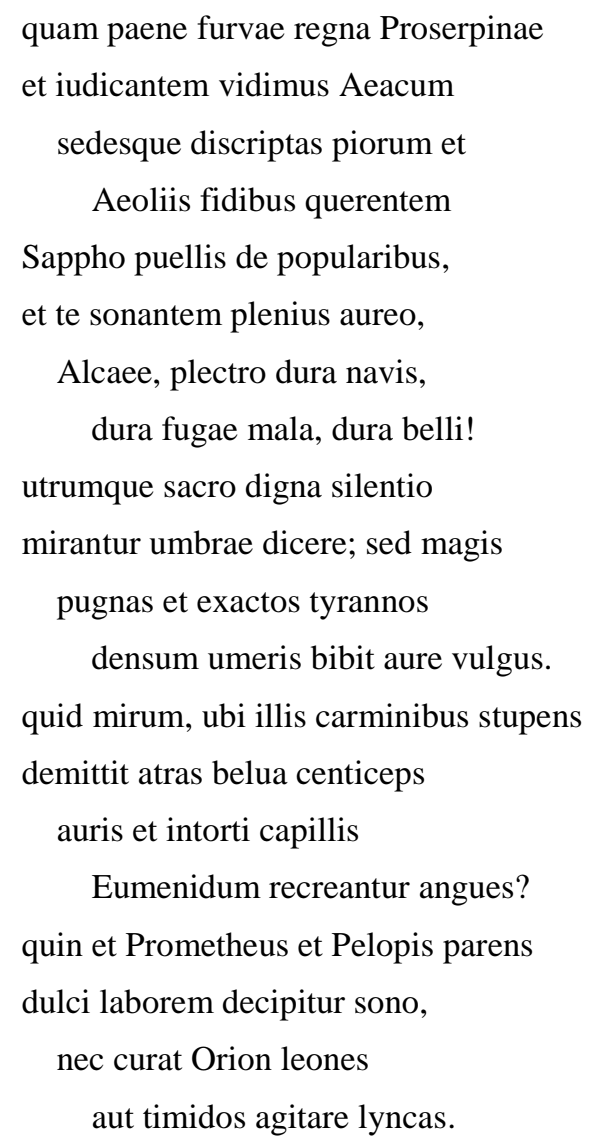

(Ode 2.13.21-40) $)^{23}$

A passagem subtrai o elemento da natureza sem subtrair o fascínio que a poesia exerce sobre seu público. Não são mais árvores ou bosques que ficam encantados pelo som

\footnotetext{
${ }^{23}$ Por pouco vimos os reinos da negra Prosérpina e Éaco, a julgar (os mortos), e as moradas separadas dos pios e, com suas cordas eólicas, Safo lamentando as meninas de seu povoado, e a ti, Alceu, entoando gloriosamente com áureo plectro as durezas do navio, as tristes durezas do exílio, as durezas da guerra. Os espectros admiram os dois a cantar coisas dignas do sagrado silêncio; porém o vulgo prefere, amontoando-se em ombros, sorver ao ouvido as lutas e os tiranos depostos. Que admirável quando, pasmando com tais cantos, a besta de cem cabeças baixa suas negras orelhas, e as serpentes retorcidas nos cabelos das Eumênides se reanimam? E até Prometeu e o pai de Pélope a penúria enganam com o doce som, e nem cuida Órion em perseguir os leões ou os tímidos linces.
} 
mágico das cordas (cf. fidibus, v. 24) dos poetas, mas sim as sombras e os monstros cuja estupefação remonta à escolha verbal virgiliana. ${ }^{24}$ As almas dos mortos e, mais importante, os condenados no mundo infernal tornam-se, aqui, ouvintes admirados de um vivo encanto poético. Poetisa e poeta históricos, ambos da ilha de Lesbos, tornam-se personagens mitológicos na lira romana de Horácio. Mais uma vez, traços reais e fictícios misturam-se na composição da res lírica.

Se, por um lado, o fracasso de Orfeu em resgatar Eurídice do reino de Prosérpina já foi lido como a impotência da linguagem da arte de esvaziar-se da subjetividade do artista, ${ }^{25}$ por outro, não há nenhuma tentativa nem fracasso similar na ode horaciana. Alceu e Safo aplacam os sofredores infernais com um canto mágico, tal qual Orfeu entoara nas Geórgicas, assim como a persona poética de Horácio sente seu ânimo apaziguado ao final da própria composição, quando a havia iniciado cheio de ira e imprecações contra quem plantara a maldita árvore (cf. ode $2.13, \mathrm{vv} .1 \mathrm{ss}.){ }^{26}$

A atmosfera infernal dos versos líricos, comum à descida de Orfeu nas Geórgicas, estabelece um curioso diálogo entre os textos e os gêneros em jogo. Todos os poetas valem-se de seus dons artísticos para aplacar mortos e condenados no mundo infernal. Seja para resgatar um amor perdido, tema tradicionalmente caro ao gênero lírico, seja para demarcar novos limites temáticos à poesia didática romana, em ambos os casos (ode lírica e poema didático) o poder da poesia atravessa o reino dos mortos e une imagens distintas de poetas por meio da leveza mitológica de suas canções. Nas palavras de Gregson Davis (1991: 87):

\begin{abstract}
Os empréstimos literários (o encanto das cobras nas Eumênides; a estupefação de Cérbero) equivale a mais que uma anuência cortês para o amigo e companheiro-poeta de Horácio. Os ecos virgilianos do motivo e da dicção ajudam a engrandecer a aura da poesia lésbia ao afiliar seus efeitos com aqueles do todo poderoso Orfeu. Essa imagem órfica do uates, quando transposta para um quadro de performance lírica, lhe confere autoridade e imprime uma marca de autenticidade.
\end{abstract}

De fato, vários paralelos verbais entre a ode e a descida de Orfeu aos infernos nas Geórgicas podem ser elencados. As "moradas dos pios" (sedes... piorum, v. 23) parece ecoar as "moradas profundas" das Geórgicas (sedibus imis, v. 4.471), assim como a formulação de

\footnotetext{
${ }^{24}$ Note-se stupens (v. 33) e, no trecho citado acima das Geórgicas (cf. nota 9), o verbo stupuere (v. 481).

${ }^{25}$ Cf. Segal (1989: 8).

${ }^{26}$ Veja-se Piccolo (2015: 272-82) para desenvolvimentos ligados à tradição épica grega.
} 
Horácio "as sombras admiram" (mirantur umbrae, v. 30) recorda as "comovidas sombras" (commotae... umbrae, vv. 471-472) de Virgílio. Até mesmo a expressão de estupefação nos dois poetas inicia-se pela conjunção quin. ${ }^{27}$ Pode-se acrescentar que Cérbero e as Eumênides são duas das figuras comuns nessa passagem pelo mundo dos mortos (com reações similares, como notou Davis), a que Virgílio acrescenta, por um lado, Ixião, ao passo que Horácio, por outro, adiciona Prometeu, Pélops e Órion a seus versos.

Mais importante do que apontar semelhanças e diferenças, contudo, é notar a poetisa Safo e o poeta Alceu travestidos de Orfeu: ao serem assimilados à figura órfica, partilhando do mesmo encanto mitológico num desolado mundo dos mortos, que carece de poesia e é por ela aplacado - como no trecho de Virgílio. É esse deleite poderoso proporcionado pela poesia, seja de Orfeu, seja dos poetas da ilha de Lesbos, que, mais uma vez, enaltece as personagens históricas, poetas reais, por meio do artifício engenhoso da comparação com Orfeu, mais sutil e velada neste último exemplo. Como se vê a seguir, não só figuras de "carne e osso", por assim dizer, se engrandecem ao serem comparadas com Orfeu. Até mesmo um deus se enaltece...

\title{
UM DEUS FANTASIADO DE ORFEU: ODE 3.11
}

\author{
Mercuri - nam te docilis magistro \\ movit Amphion lapides canendo - \\ tuque testudo resonare septem \\ callida nervis, \\ nec loquax olim neque grata, nunc et \\ divitum mensis et amica templis, \\ dic modos, Lyde quibus obstinatas \\ applicet auris, \\ quae velut latis equa trima campis \\ ludit exsultim metuitque tangi, \\ nuptiarum expers et adhuc protervo \\ cruda marito. \\ tu potes tigris comitesque silvas \\ ducere et rivos celeris morari; \\ cessit immanis tibi blandienti
}

${ }^{27}$ Comparem-se a última estrofe da ode (vv. 37-40) e os três versos das Geórgicas, citados acima (cf. nota 9). 


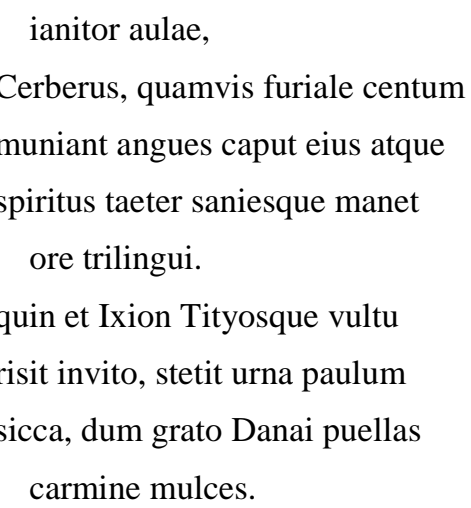

$(\text { Ode } 3.11 .1-24)^{28}$

Essa "longa" ode costuma ser dividida em duas metades. Na primeira, o eu lírico invoca Mercúrio e sua lira (em sua ancestral forma de tartaruga, cf. testudo, v. 3) para adoçar os ânimos da amada Lide, que aparenta inexperiência no trato com os homens. Na segunda, ele passa a reportar a fala condoída de Hipermnestra, a única dentre as cinquenta Danaides que desrespeita o acordo paterno e, diferente de suas irmãs, não mata o marido na noite de núpcias. A menção às Danai puellas (meninas de Dânao), no verso 23, faz a transição entre os dois trechos.

A primeira parte do poema, contudo, ainda intriga analistas. ${ }^{29}$ Para uns, soa como mera introdução à segunda metade, cuja fábula teria a função de exortar Lide ao amor. ${ }^{30}$ Para outros, como uma oração em estilo formal à divindade que se desvia de sua função no meio do caminho. Para outros, um apelo por inspiração, num irônico hino de casamento para uma noiva relutante. Para mim, contudo, as duas partes do poema se equilibram: a metapoesia da primeira metade complementa a poesia "em prática" na segunda; ou seja, o pano de fundo poético, propiciado pelo início "laudatório" da ode, torna-se plena ação poética do meio até o

\footnotetext{
${ }^{28}$ Ó Mercúrio - pois, tu como mestre, dócil Anfião moveu as pedras cantando - e tu, lira-quelônia, hábil a ressoar com sete cordas, dantes nem loquaz nem graciosa, ora amável para as mesas dos ricos e para os templos, entoa ritmos a que Lídia preste atentos seus ouvidos: qual égua nova em campos vastos brinca saltitando e teme ser tocada, desconhece as núpcias e (está) ainda crua a um marido de ímpeto. Tu podes levar tigres como companheiros e bosques, e retardar rios céleres. Parou por teus encantos o gigante guardião do palácio, Cérbero, embora às centenas serpes muniam-lhe a cabeça furial, e um hálito negro e peçonha emanem de sua boca trilíngue. Até Íxião e Tício com rosto invito riram, e por pouco parou a urna seca ao abrandares com verso agradável as filhas de Dânao.

${ }^{29}$ Confrontem-se, por exemplo, Pasquali (1920: 144), Fraenkel (1957: 196ss.), Williams (1969: 81ss.), Quinn (1980: 264), West (2002: 100ss.) e uma nota em Falcão (2008: 213).

${ }^{30} \mathrm{Ou}$, nas palavras de Pasquali (1920: 300), um valor parenético. Mas uma longa introdução, vale dizer.
} 
fim do poema. Horácio louva os dotes poéticos de Mercúrio e tais qualidades exemplificam-se na fábula (literalmente, na fala) de Hipermnestra.

Sob a forma de um hino de invocação (klêtikòs hymnos) ao inventor da lira, a ode 3.11 estende-se, em sua primeira parte, sobre as proezas poéticas de Mercúrio com seu instrumento: vale lembrar que Hermes já ajudara Zeus em seus vários casos amorosos, segundo a tradição mitológica, e talvez Horácio se lembre disso ao invocá-lo com a lira de sete cordas. A carga misteriosa associada ao número sete traz um elemento em comum entre os versos de Horácio e Virgílio: Mercúrio e Orfeu tangem uma lira de sete cordas. ${ }^{31}$ Eis que, para exaltar o deus como poeta exímio, Horácio aproxima-o ao máximo da imagem do poeta Orfeu. Num hino convencional, como na ode 1.10, dedicada a Mercúrio, convém que o poeta passe por fórmulas tradicionais em sua composição, como a menção da linhagem nobre do deus, a ênfase nos vários feitos insignes, a repetição da invocação-interlocução para com a divindade etc. $^{32}$ Diferente de 1.10 , na ode 3.11 , Horácio concentra-se exclusivamente na habilidade poética de Mercúrio, invocado para auxiliá-lo na conquista de Lide.

Duas descrições características e distintas do poeta mitológico são mencionadas nos versos acima: o encanto poético capaz tanto de conduzir os elementos da natureza (vv. 13-4), fazendo que tigres e bosques o sigam ou retardando os céleres rios, quanto de enfeitiçar os seres infernais, que se iniciam por Cérbero (vv. 15ss.). A imagem canina, não obstante seu traço bestial, propicia uma transição adequada entre as duas características: da natureza selvagem (qual os tigres) para um cão feroz que está nos infernos. Eis que tal encanto poético vem aplacá-lo, e também aos célebres condenados, como Ixião, Tício e as Danaides similarmente aos vários trechos citados.

Lembre-se de que, na ode 1.24, Mercúrio é retratado como uma divindade cruel (cf. non lenis, v. 17), que tange implacavelmente as almas dos mortos aos infernos. ${ }^{33}$ Todavia, em 3.11, o mesmo deus encanta os condenados no submundo infernal com os poderes órficos de sua lira, presente à humanidade junto com a linguagem, como canta a ode 1.10. Se, nesse hino a Mercúrio há menos espaço para ousadias poéticas formais, é na ode 3.11 que Horácio une

\footnotetext{
${ }^{31}$ Sobre as cordas e seu número sete, confrontem-se septem nervis (vv. 3-4) na ode, e os numeris septem discrimina na Eneida 6.646.

${ }^{32}$ Notem-se, na ode 1.10: a) nepos Atlantis (v. 1); b) as duas primeiras estrofes com os dons de Mercúrio aos homens; c) a repetição dos pronomes te e $t u$ nos versos 5, 9, 12 e 17.

${ }^{33}$ Cf. acima nota 16. Vale o confronto com a estrofe final da ode 1.10, em que o papel de psychagōgós ("condutor de almas") também aparece.
} 
duas partes desiguais ao compor um poema mais extenso, atenuando as fronteiras entre o poético e o metapoético, o divino e o mitológico, a poésis e a práxis poética. $\mathrm{O}$ alcance do conhecimento poético na ode corresponde ao poder do deus sobre seus domínios, naturais e sobre-humanos. Ver a si como poeta é vislumbrar-se como um deus. O sucesso divino sobre a linguagem reflete-se sobre o sucesso trazido pela comparação com Orfeu, levada aos limites que opõem os reinos da existência e da consciência, da vida e da morte.

Como no filme de Jean Cocteau (Orphée 1950), o liame da morte disfarça-se na superfície do espelho. Atravessá-lo é também adentrar um labirinto. A entranha de tais símbolos mistura-se às fronteiras da palavra poética: a alusão transmuda-se em novas imagens que aludem, por sua vez, a outros poemas, imagens e alusões. A rede de menções a Orfeu tonifica a imagem mítica do poeta que enfeitiça e paralisa tudo e a todos com o encanto de sua lira, sem desqualificar seu mito nem desmistificá-lo como personagem ou poeta.

Se Orfeu incorpora o poeta que realizou as mais célebres proezas possíveis com uma lira, mascarar o deus Mercúrio como Orfeu significa, sim, exaltar as qualidades poéticas do mesmo deus que criou a lira e, por conseguinte, a própria poesia (em sua vertente lírica, alguns diriam). Não há paradoxo: Orfeu consagrou-se como poeta mítico pelo trabalho que tantos escritores e poetas lhe dedicaram. De forma análoga, equiparar Alceu, Safo, Virgílio ou Píndaro a Orfeu significa louvar os sublimes atributos poéticos de cada um desses autores - o que nos leva a pensar o próprio Horácio também como um consagrado Orfeu.

\section{REFERÊNCIAS BIBLIOGRÁFICAS}

\section{Fontes primárias}

HORATIUS FLACCUS, Q. Opera. Instruxit Eduardus C. Wickham, curante H. W. Garrod. Clarendon Press, Oxford, 1901.

MEYER, G. Pomponii Porphyrionis commentarii in Q. Horatium Flaccum. Teubner, Leipzig, 1874.

PROPERTIUS, S. Elegos. Edidit S. J. Heyworth, Clarendon Press, Oxford, 2007.

VERGILIUS MARO, P. Opera. Instruxit R.A.B. Mynors. Clarendon Press, Oxford, 1969. 


\section{Fontes secundárias}

BENVENISTE, E. (1969). Le vocabulaire des institutions indo-européennes. Vol. 2: pouvoir, droit, religion. Les éditions de minuit, Paris.

BRINK, O. (1971). Horace on Poetry: The ‘Ars Poetica'. Cambridge U. P., Cambridge.

BURGESS, J. S. (2005) “The epic cycle and fragments.” A companion to Ancient epic edited by John Miles Foley. Blackwell publishing, Oxford.

CAVARZERE, A. (1996). Sul limitare: il motto e la poesia di Orazio. Pàtron Editore, Bologna.

CONTE, G. B. (1986). “Aristaeus, Orpheus, and the Georgics”. In: The Rhetoric of Imitation: Genre and Poetic Memory in Virgil and Other Latin Poets. Cornell University Press, Ithaca/ London, pp. 130-40.

CONTE, G. B. (2007). “Aristaeus, Orpheus, and the Georgics: once again”. In: The Poetry of Pathos. Edited by Stephen J. Harrison. Oxford U. P., Oxford.

DAVIS, G. (1991). Polyhymnia: the Rhetoric of Horatian Lyric Discourse. University of California Press, Berkeley and Oxford.

FALCÃO, P. B. (2008). Horácio: Odes. Livros Cotovia, Lisboa.

FRAENKEL, E. (1957). Horace. Clarendon Press, Oxford.

GRIMAL, P. (1993). Dicionário da mitologia grega e romana. $2^{\mathrm{a}}$ Edição. Editora Bertrand Brasil, Rio de Janeiro.

HOLZBERG, N. (2007). Horaz: Eine Bibliographie. Disponível em: <http://www.klassphil.uni-muenchen.de/worddokumente/holzberghorazbibl.doc>. Acesso em: 20 mar. 2015.

LOURENÇO, F. (2006). Poesia Grega: de Álcman a Teócrito. Livros Cotovia, Lisboa.

NISBET, R.; HUBBARD, M. (1970). Horace Odes Book I: a commentary. Clarendon Press, Oxford.

NISBET, R.; HUBBARD, M. (1978). Horace Odes Book II: a commentary. Clarendon Press, Oxford.

OGDEN, D. (2007). A companion to Greek religion. Blackwell publishing, Oxford.

PASQUALI, G. (1920). Orazio Lirico. Felice Le Monnier, Firenze. 
PICCOLO, A. P. (2015). O arco e a lira: modulações da épica homérica nas Odes de Horácio. Campinas. 405pp. Tese de doutorado. Unicamp.

QUINN, K. (1980). Horace: The Odes. St. Martin's Press, London.

SEGAL, C. (1989). Orpheus: the myth of the poet. The John Hopkins University Press, Baltimore and London.

SOUZA, E. (2013). Catábases: estudos sobre viagens aos infernos na Antiguidade. Annablume, São Paulo.

WEST, D. (2002). Horace Odes III: Dulce Periculum. Oxford U. P., Oxford.

WILLIAMS, G. (1969). The 3rd Book of Horace's Odes. Clarendon Press, Oxford. 